\title{
Labour and delivery complications
}

\section{and schizophrenia}

\author{
Case-control study using contemporaneous labour ward \\ records
}

\section{MAJELLA BYRNE, ROY BROWNE, NIAMH MULRYAN, ANN SCULLY, MARY MORRIS, ANTHONY KINSELLA, NORIYOSHI TAKEI, TOM MCNEIL, DERMOT WALSH and EADBHARD O'CALLAGHAN}

\author{
Background Controversy continues \\ regarding an association between \\ obstetric complications and risk of \\ schizophrenia in early adult life.
}

\begin{abstract}
Aims To compare the rate of labour and delivery complications among persons who developed schizophrenia with controls; to establish whether any complication is associated with later schizophrenia.
\end{abstract}

\begin{abstract}
Method We located the labour ward records of 431 individuals with schizophrenia and of same-gender controls from the same hospital birth series. Mothers were matched by age, socio-economic group and parity. Individual complications were evaluated blindly using two obstetric complication scales.
\end{abstract}

Results Overall, the rate of labour and delivery complications for those who developed schizophrenia did not differ from that of controls. Males who had presented to psychiatric services before the age of 30 had a greater frequency of and more severe labour/delivery complications than their matched controls.

\section{Conclusions Other than among young-onset males we found no increase in labour and delivery complications among cases.}

Declaration of interest This study was funded by the Health Research Board of Ireland and the Stanley Foundation.
Although a genetic basis for schizophrenia is now virtually undisputed (Cardno et al, 1999), cohort studies have provided evidence both for (Hultman et al, 1997; Jones et al, 1998; Dalman et al, 1999) and against (Done et al, 1991; Buka et al, 1993) an association between obstetric adversity and later development of the disease. In a meta-analysis, Geddes \& Lawrie (1995) concluded that while there was some evidence of an association, there was also evidence for publication bias, as relatively few small negative studies had been published. Many studies within that metaanalysis had small numbers of index cases, relied on maternal recall of obstetric complications and failed to control for social class at the time of birth. We set out to address some of these methodological difficulties by using contemporaneous birth records of patients from a geographically defined case register and closely matched controls.

\section{METHOD}

\section{Subjects}

The Dublin Psychiatric Case Register is based on an integrated community service for a population of approximately 253000 . A specialist team compiles data for all inpatient and out-patient contacts with the psychiatric services. We initially selected 1779 Dublin-born patients who had been given an ICD-9 (World Health Organization, 1978) diagnosis of schizophrenia (ICD-9 295.0-295.9) between 1972 and 1992. Four hundred and thirty-one cases were included in the final analyses. The reasons for excluding cases are shown in Table 1.

\section{Birth records}

The maternity hospital labour ward diary detailed the following: parental names; age of mother; parity, number of pregnancies, length of gestation; paternal occupation; gender of child; date of birth; mode of delivery; presentation; whether twin or singleton; birth weight; premature rupture of membranes; nature of labour; hours in labour; child's and mother's health immediately after delivery; transfer to baby unit; immediate baptism. The diary, including a free-text record of the birth and delivery, was recorded verbatim. Similar data relating to home births, including a 9-day follow-up record of the baby's health, were also recorded.

\section{Controls}

The previous same-gender singleton live birth recorded in the labour ward diary, matched for maternal age, parity, social class and home/hospital birth, was selected as a control. The maternal age of the index case \pm 2 years was chosen as the age cut-off point for the maternal control. Parity status was classified as follows: prima gravida (first delivery), multi gravida (2-4 deliveries) or grand multi gravida (more than four deliveries). Social class, based on paternal occupation, was matched according to the classification system of O'Hare et al (1991), which is also used by the Irish Central Statistics Office. One of the hospitals did not record paternal occupation, so where possible we obtained this information from the General Register Office birth register. Because we were unable to establish whether controls lived to the age at which the risk of developing schizophrenia occurs, we identified 22 deaths in the first year of life in the General Register Office death register and replaced them with appropriate controls. All birth records were rated blindly according to two obstetric complication scales, scale 1 (Lewis et al, 1989) and scale 2 (Parnas et al, 1982).

\section{Analyses}

Individual items from the obstetric complication scales were analysed separately using matched pairwise techniques. Odds ratios (ORs) and confidence intervals (CIs) were calculated for binary variables. Conditional logistic regression was used to compute for the development of the disorder after allowing for case-control matching. This procedure was repeated for each of the items in the separate scales. 
Cases lost to Sample size Percentage of sample that are sample $\quad(n) \quad$ searchable singleton maternity hospital births

\begin{tabular}{lccc}
\hline Register & - & 1779 & - \\
Insufficient register data to allow tracing & 349 & 1430 & - \\
Estimate of sample not born in study & 283 & 1147 & - \\
$\quad$ hospitals (19.8\%) & & & $49 \%$ \\
Twin births & 40 & 1107 & $39 \%$ \\
Found cases & - & 541 & 431 \\
Missing social class data for matching & 110 &
\end{tabular}

Percentages are based on singleton births available to study.

Table 2 Matching criteria: a comparison of cases and controls $(n=43 \mathrm{I})$

\begin{tabular}{lcccc}
\hline Criterion & Cases & Controls & Tor $z$ & $P$ \\
\hline Maternal age (years) & $30.7($ s.d. $=5.9)$ & $30.6($ s.d. $=5.8)$ & $T=0.88$ & $0.38^{\prime}$ \\
Number of pregnancies & $3.98($ s.d. $=2.9)$ & 3.91 (s.d. $=2.9)$ & $T=-0.78$ & $0.44^{\prime}$ \\
Social class & $4.98($ s.d. $=1.2)$ & $4.98($ s.d. $=1.2)$ & $z=-0.02$ & $0.98^{2}$ \\
\hline
\end{tabular}

I. Paired $t$-tests.

2. Mann-Whitney $U$-test.

\section{RESULTS}

The final study group comprised 431 cases (256 males, 175 females). This group had fewer married females and fewer in the higher social classes than the original selection. Cases were indistinguishable from controls in terms of maternal age, maternal parity and social class of origin (Table 2).

\section{Scales}

Cases did not differ from controls on scale 1 in terms of either definite (OR 1.05,
95\% CI $0.72-1.54, P=0.85$ ) or equivocal (OR $0.92,95 \%$ CI $0.61-1.40, P=0.76$ ) complications. Because we were evaluating contemporaneous labour ward records rather than depending on maternal recall, we also combined the definite and equivocal complications categories and found no difference between patients and controls. Similarly, scale 2 did not distinguish between cases and controls in terms of frequency, severity or total complications score.

In the light of previous findings (O’Callaghan et al, 1992; Kirov et al,
1996; Verdoux et al, 1997; Smith et al, 1998) we split the study groups by age at first diagnosis and gender and found that only males diagnosed with schizophrenia before the age of 30 (Table 3) had a greater number of definite complications than controls on scale 1 . Similarly, using scale 2 , male patients had a higher frequency of and more severe complications than their matched controls (Table 4).

\section{Individual complications}

The specific complications of Caesarean section (OR 4.00, 95\% CI 1.08-22.1, $P=0.04$ ) and narrow pelvis (OR 7.00, $95 \%$ CI $0.90-320, P=0.07$ ) distinguished patients from controls. The individual complications, classified by gender and age of presentation, for each scale are shown in Tables 5 and 6. We found that Caesarean section (both emergency and not otherwise specified (NOS)) distinguished between cases and controls (OR $7.82 \times 10^{14}, 95 \%$ CI $0-0, P=0.004)$ and was specific to males. Those born by Caesarean section presented to the psychiatric services at a significantly younger age (mean 24.01 years, s.d. $=6.3 ; T=3.76, P=0.003)$ than those born by normal delivery (mean 31.4 years, s.d.=10.6). Conditional logistic regression analysis of the males confirmed that only Caesarean section was significant $(\log$ likelihood removal $=354.9$, d.f. $=1$, $P \leqslant 0.001)$ in differentiating between cases and controls. For females, only low birth weight $(\log$ likelihood removal $=242.6$, d.f. $=1, \quad P=0.002$ ) distinguished between the two groups.

Table 3 Obstetric complication scale I: summary scores (Lewis \& Murray, 1989)

\begin{tabular}{|c|c|c|c|c|c|c|}
\hline \multirow[t]{2}{*}{ Scale I } & \multicolumn{3}{|c|}{ Males } & \multicolumn{3}{|c|}{ Females } \\
\hline & Cases & Controls & OR $(95 \% \mathrm{Cl})^{\prime}$ & Cases & Controls & OR $(95 \% \mathrm{Cl})^{\prime}$ \\
\hline \multicolumn{7}{|l|}{ Total } \\
\hline Definite complication ${ }^{2}$ & $50: 206$ & $37: 219$ & I.4I (0.88-2.27) & $22: 153$ & $32: 143$ & $0.64(0.36-1.16)$ \\
\hline Equivocal complication & $51: 205$ & $46: 210$ & $\mathrm{I} .13(0.70-1.8 \mathrm{I})$ & $19: 156$ & 28:147 & $0.56(0.26-1.20)$ \\
\hline Any complication ${ }^{3}$ & $84: 172$ & $74: 182$ & I.2I (0.8I-I.83) & $35: 140$ & $52: 123$ & $0.53(0.30-0.94)^{*}$ \\
\hline \multicolumn{7}{|c|}{ Cases presenting at age $<30$ years } \\
\hline Definite complication & $36: 105$ & $19: 122$ & $2.27(1.12-4.62)^{*}$ & $14: 70$ & $18: 66$ & $0.85(0.38-I .89)$ \\
\hline Equivocal complication & $36: 105$ & $35: 106$ & $0.95(0.56-1.93)$ & 10.74 & $12: 72$ & $0.83(0.25-2.73)$ \\
\hline Any complication & 59:82 & $45: 96$ & $1.61(0.89-2.90)$ & $19: 65$ & $26: 58$ & $0.69(0.30-1.62)$ \\
\hline
\end{tabular}

I. Cases v. controls.

2. Definite and equivocal complications as per scale of Lewis et al (1989).

3. Any complication: combined definite and equivocal scores.

$* P<0.05$. 
Table 4 Obstetric complication scale 2: summary scores (Parnas et al, 1982)

\begin{tabular}{|c|c|c|c|c|}
\hline \multirow[t]{2}{*}{ Scale 2} & \multicolumn{2}{|c|}{ Males } & \multicolumn{2}{|c|}{ Females } \\
\hline & $\mathbf{z}$ & $P$ & $\mathbf{z}$ & $P$ \\
\hline \multicolumn{5}{|l|}{ Total } \\
\hline Frequency of complications' & -2.05 & 0.04 & -0.68 & 0.50 \\
\hline Severity score & -1.46 & 0.15 & -0.60 & 0.55 \\
\hline Total score & -1.60 & 0.11 & -0.38 & 0.71 \\
\hline \multicolumn{5}{|c|}{ Cases presenting at age $<30$ years } \\
\hline Frequency of complications & -2.46 & 0.01 & -0.91 & 0.36 \\
\hline Severity score & -2.06 & 0.04 & -0.74 & 0.46 \\
\hline Total score & -2.19 & 0.03 & -0.71 & 0.48 \\
\hline
\end{tabular}

I. Frequency score based on scale of Parnas; severity score rated according to scale; total score - combined severity scores for each complication present. Wilcoxon matched pair signed rank tests of cases $v$. controls.

\section{DISCUSSION}

\section{Limitations}

The patients received a clinical discharge diagnosis by a psychiatrist according to ICD-8 (World Health Organization, 1974) or ICD-9 rather than a research diagnosis. Less than $50 \%$ of the targeted sample were found, more male than female birth records were identified and the age at first diagnosis was younger for located cases. These results could be accounted for by our inability to trace the birth records of married females. Some home births were excluded because their records contained insufficient detail. Social class is related to obstetric outcome (Wilcox et al, 1995), so we excluded 110 cases that could not be matched adequately for social class of origin. Finally, the labour ward diaries contained only limited information on early pregnancy and the postnatal period.

\section{Scales and individual labour and delivery complications}

Despite applying two frequently used obstetric complication scales we failed to find differences between cases and controls in terms of overall complication scores. There is an apparent difference between these overall results and other large studies in this field (Kendell et al, 1996; Hultman et al, 1997). One potential explanation for the contradictory results may lie in the patient selection procedures. Many case-control and cohort studies (Done et al, 1991; McCreadie et al, 1992; Verdoux \& Bourgeois, 1993; Kendell et al, 1996) have relied on information from patients born in recent years when either their mothers were alive or birth records, particularly computerised information, were available. Such patients are more likely to have had a young age at onset. While this study indicates that young male patients do have an excess of obstetric complications we failed to find any general effect of obstetric adversity among persons developing the disorder.

Persons who later developed schizophrenia were more likely to have been born by Caesarean section. This finding complements those of the recent meta-analysis by Verdoux et al (1997) and a National Register study in Denmark (Bennedsen et al, 1998), although in the present study the effect was confined to males. We confirm, using a case register study, the meta-analysis result (Verdoux et al, 1997) that Caesarean section is related to a younger age at first presentation with schizophrenia.

Although this association is interesting, the complication itself is non-specific. Caesarean section is the result of the obstetrician's judgement to intervene in response to a variety of potential risks. Most of the patients in this study were born when the rate of Caesarean section was less than $3 \%$ and was rarely an elective procedure. The commonest recorded reasons for section were major antepartum haemorrhage, deep transverse arrest or failure of labour to progress where foetal distress was apparent. Cephalopelvic disproportion was noted in $25 \%$ of cases born by Caesarean section, and a clinical note recording 'narrow pelvis' was found more frequently among cases than among controls.

One of the commonest reasons for a narrow maternal pelvis is poor nutrition during adolescence. Mothers born and raised in Third World countries who migrated to the USA are on average shorter and have narrower pelvic dimensions than mothers born in the USA. Those immigrant women who eat a high-protein diet and receive adequate prenatal care give birth to relatively large infants, which results in cephalopelvic disproportion and severe dystocia (Abitbol et al, 1997). In addition to the direct effects of malnutrition (Susser \& Lin, 1992), cephalopelvic disproportion merits consideration as a nutritionally related risk factor, particularly for groups previously described as having increased risk of schizophrenia (Warner, 1995; Harrison et al, 1997).

The reported palatal (O'Callaghan et al, 1991; Cantor-Graae et al, 1994; Lane $e t$ al, 1997) and craniofacial abnormalities among patients with schizophrenia may not entirely result from genetic factors, as we considered previously but may be related to a moulding process in a narrow pelvis (de la Fuente, 1991). However, a narrow pelvis in itself does not necessarily result in damage to the foetus, since when identified it commonly results in operative delivery.

Among patients, a gestational age of less than 37 weeks occurred more frequently among males whose first diagnosis was before the age of 30 . While this result has been reported previously (Jones et al, 1998), such cases, as with Caesarean section and cephalopelvic disproportion, accounted for a modest proportion of our study group. Indeed, despite several individual complications being associated with the later development of schizophrenia, the proportion of cases affected was extremely small, indicating that obstetric adversity is not associated with the majority of cases of schizophrenia, especially when the age at onset is over 30 years.

Although this paper describes a large case-control study which used contemporaneous records, the fact that many individual labour and delivery complications occur at a frequency of less than $10 \%$ in the general population suggests that the crossreferencing of population-based obstetric databases with psychiatric case registers is necessary in order to address definitively the contribution of individual complications to the risk of schizophrenia.

\section{ACKNOWLEDGEMENTS}

We thank the staff and clinicians of the Dublin Psychiatric Case Register and the masters and filing staff of the four hospitals included in this study. We are grateful for permission from the Minister of Health to access the General Registry Office (GRO) records and to the staff of the GRO for assisting us. Permission was kindly granted by the Masters of the three major Dublin maternity hospitals (the National Maternity Hospital and Rotunda and 


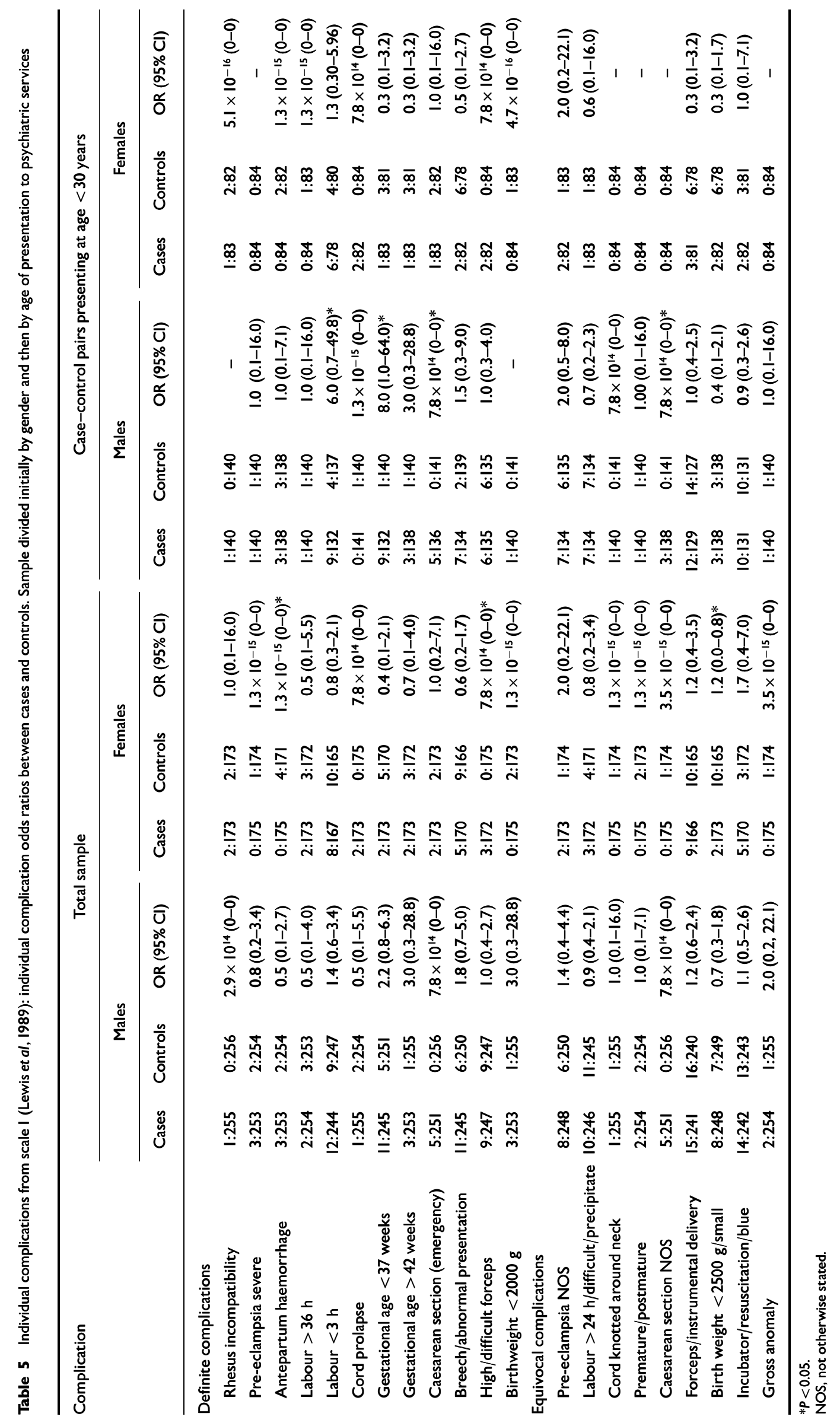




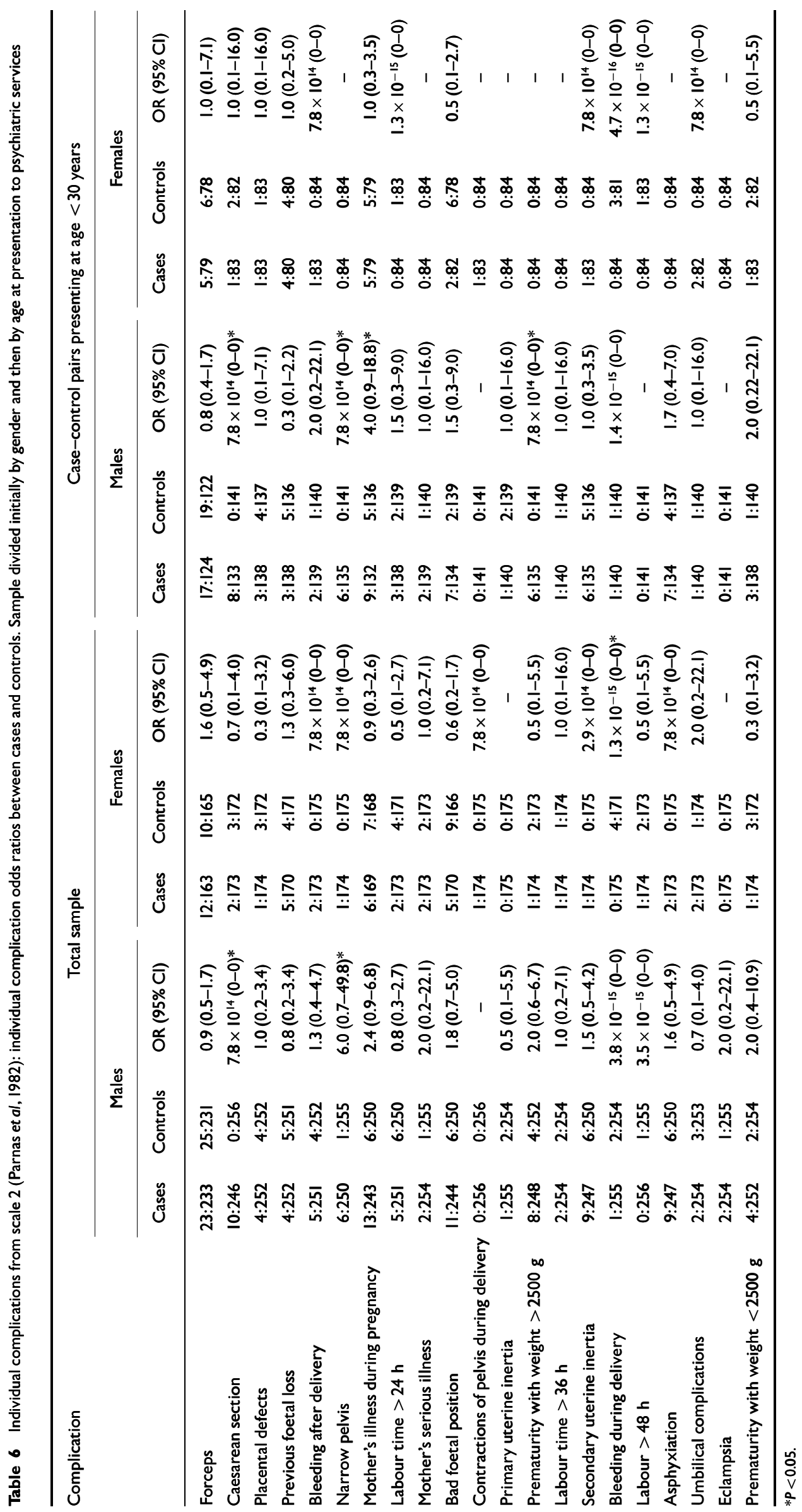


Coombe Hospitals) to access labour ward diaries, which have been retained at each hospital since 1896. Additionally, we were granted access to the maternity unit of St James's Hospital which, although no longer functioning as an obstetric unit, has retained some records.

\section{REFERENCES}

Abitbol, M. M., Taylor-Randall, U. B., Barton, P.T., et al (1997) Effect of modern obstetrics on mothers from Third-World countries. Journal of Maternal and Fetal Medicine, 6, 276-280.

Bennedsen, B. E., Mortensen, P. B. \& Olesen, A.V. (1998) Adverse pregnancy outcomes among schizophrenic women. Schizophrenia Research, 29, 14.

Buka, S. L., Tsuang, M. T. \& Lipsitt, L. P. (1993) Pregnancy/delivery complications and psychiatric diagnosis: a prospective study. Archives of General Psychiatry, 50, 151-156.

Cantor-Graae, E., McNeil, T. F., Torrey, E. F., et a

(1994) Link between pregnancy complications and minor physical anomalies in monozygotic twins discordant for schizophrenia. American Journal of Psychiatry, 15I, ||88-1193.

Cardno, A. G., Marshall, E. J., Coid, B., et al (1999) Heritability estimates for psychotic disorders: the Maudsley twin psychosis series. Archives of General

Psychiatry, 56, 162-168.

Dalman, C., Allebeck, P., Cullberg, J., et al (1999) Obstetric complications and the risk of schizophrenia. A longitudinal study of a national birth cohort. Archives of General Psychiatry, 56, 234-240.

de la Fuente, A. A. (1991) Locking and reverse molding of the fetal skull. Pediatric Pathology, II, 27I-280.

Done, D. J., Johnstone, E. C., Frith, C. D., et al (1991) Complications of pregnancy and delivery in relation to psychosis in adult life: data from the British perinatal mortality survey sample (comments). British Medical Journal, 302, 1576-1580.

Geddes, J. R. \& Lawrie, S. M. (1995) Obstetric complications and schizophrenia: a meta-analysis. British Journal of Psychiatry, 167, 786-793.

Harrison, G., Glazebrook, C., Brewin, J., et al (1997) Increased incidence of psychotic disorders in migrants from the Caribbean to the United Kingdom. Psychological Medicine, 27, 799-806.

Hultman, C. M., Öhman, A., Cnattingius, S., et al (1997) Prenatal and neonatal risk factors for schizophrenia. British Journal of Psychiatry, 170, 128-133.

Jones, P. B., Rantakallio, P., Hartikainen, A. L., et al (1998) Schizophrenia as a long-term outcome of pregnancy, delivery, and perinatal complications: a 28 year follow-up of the 1966 north Finland genera population birth cohort. American Journal of Psychiatry, 155, 355-364

Kendell, R. E., Juszczak, E. \& Cole, S. K. (1996) Obstetric complications and schizophrenia: a case control study based on standardised obstetric records. British Journal of Psychiatry, 168, 556-561.

Kirov, G., Jones, P. B., Harvey, L., et al (1996) Do obstetric complications cause the earlier age at onset in male than female schizophrenics? Schizophrenia Research 20, $117-124$.

Lane, A., Kinsella, A., Murphy, P., et al (1997) The anthropometric assessment of dysmorphic features in schizophrenia as an index of its developmental origins. Psychological Medicine, 27, II55-1164.

\section{CLINICAL IMPLICATIONS}

- Labour and delivery complications are relevant to some, but certainly not all, patients with schizophrenia.

- Delivery by Caesarean section was more common among patients than controls and was associated with a younger age at first diagnosis among males.

Male cases were more frequently associated with complications.

\section{LIMITATIONS}

Only $49 \%$ of the estimated number of traceable records were found.

- The study was confined to labour and delivery complications. Only limited data for the pregnancies and perinatal period were identified.

- Despite the sample size, we believe that the power of the present study was limited.

MAJELLA BYRNE, MSc, ROY BROWNE, Cluain Mhuire Community Psychiatric Service, Dublin, Ireland; NIAMH MULRYAN, MRCPsych, ANN SCULLY, MRCPsych, St Loman's Hospital, Dublin, Ireland; MARY MORRIS, BSc; ANTHONY KINSELLA, FIS, Dublin Institute of Technology, Dublin, Ireland; NORIYOSHI TAKEI, PhD, Hamamatsu University School of Medicine, Hamamatsu, Japan; TOM McNEIL, PhD, Department of Public Health, Lund University, Sweden; DERMOT WALSH, FRCPsych, St Loman's Hospital, Dublin, Ireland, and Department of Public Health, Lund University, Sweden; EADBHARD O'CALLAGHAN, FRCPsych, Cluain Mhuire Community Psychiatric Service, Dublin, Ireland

Correspondence: Dr E. O'Callaghan, Cluain Mhuire Community Psychiatric Service, Newtownpark Avenue, Blackrock, Co. Dublin, Ireland. Tel: +353-I-283 3766; fax: +353-I-283 3886; e-mail: eadbhard@indigo.ie

(First received 12 April 1999; final revision 23 August 1999, accepted 26 August 1999)

Lewis, S. W., Owen, M. J. \& Murray, R. M. (1989)

Obstetric complications and schizophrenia: methodology and mechanisms. In Schizophrenio: Scientific Progress (eds S. C. Schulz \& C. A. Tamminga), pp. 56-68. Oxford: Oxford University Press.

McCreadie, R. G., Hall, D. J., Berry, I. J., et al (1992) The Nithsdale schizophrenia surveys. X: Obstetric complications, family history and abnormal movements. British Journal of Psychiatry, 160, 799-805.

O’Callaghan, E., Larkin, C., Kinsella, A., et al (1991) Familial, obstetric, and other clinical correlates of minor physical anomalies in schizophrenia. American Journal of Psychiatry, 148, 479-483.

,Gibson, T., Colohan, H. A., et al (1992) Risk of schizophrenia in adults born after obstetric complications and their association with early onset of illness: a controlled study. British Medical Journal, 305 1256-1259.

O'Hare, A., Whelan, C. T. \& Commins, P. (1991) The development of an Irish census-based social class scale. The Economic and Social Review, 22, 135-136.

Parnas, J., Schulsinger, F., Teasdale, T.W., et al (1982) Perinatal complications and clinical outcome within the schizophrenia spectrum. British Journal of Psychiatry, $\mathbf{1 4 0}$ 416-420.

Smith, G. N., Kopala, L. C., Lapointe, J. S., et al (1998) Obstetric complications, treatment response and brain morphology in adult-onset and early-onset males with schizophrenia. Psychological Medicine, 28, 645-653.

Susser, E. S. \& Lin, S. P. (1992) Schizophrenia after prenatal exposure to the Dutch Hunger Winter 1944-1945. Archives of General Psychiatry, 49, 983-988.

Verdoux, H. \& Bourgeois, M. (1993) A comparative study of obstetric history in schizophrenics, bipolar patients and normal subjects. Schizophrenia Research, 9 67-69.

_ , Geddes, J. R., Takei, N., et al (1997) Obstetric complications and age at onset in schizophrenia: an international collaborative meta-analysis of individua patient data. American Journal of Psychiatry, 154, 1220-1227.

Warner, R. (1995) Time trends in schizophrenia: changes in obstetric risk factors with industrialization. Schizophrenia Bulletin, 2I, 483-500.

Wilcox, M. A., Smith, S. J., Johnson, L. R., et al (1995) The effect of social deprivation on birthweight excluding physiological and pathological effects. British Journal of Obstetrics and Gynaecology, 102, 918-924.

World Health Organization (1974) The Eighth Revision of the International Classification of Diseases and Related Health Problems (ICD-8). Geneva: WHO.

- (1978) The Ninth Revision of the International Classification of Diseases and Related Health Problems (ICD-9). Geneva: WHO. 